\title{
Critical care doctors want escalated pandemic planning
}

$\mathrm{C}$ ritical care physicians are calling on Canada to "substantially" escalate its response to pandemic (H1N1) 2009, in preparation for a second wave of the influenza that is likely to cause severe lung injuries in a subset of patients and could exceed the capacity of the country's intensive care units.

"It's exceedingly likely that come the late summer, early fall, there is going to be much more H1N1-A and the absolute number of patients are going to be a lot higher. It may very well exceed our capacity and our plan to care for them," says Dr. Rob Fowler, a critical care physician at Sunnybrook Hospital in Toronto, Ontario. "Our response needs to be escalated substantially more than we're doing right now."

Fowler, a member of the Canadian Critical Care Trials Group, is gathering case descriptions of critically ill patients in ICUs across the country. His report will describe the patients' clinical presentation, treatment challenges and outcomes. About half the patients whose data Fowler and colleague Dr. Anand Kumar have collected were treated in Manitoba. Quebec, Ontario and Alberta have seen the next largest concentrations of critically ill patients. In addition, Fowler has access to data from Mexico's critical care group. The picture emerging from Mexico is of an influenza that largely affects people aged 10-55, with a core group of patients typically in their 40s who have developed acute lung injuries and hypoxic respiratory failure.

"We're seeing a very similar thing, and in a subset of patients, severe lung injury requiring extraordinary support in intensive care, with means to oxygenate that a lot of the world doesn't have, and is in limited supply in Canada," Fowler says.

These patients have required aggressive and unconventional means of oxygenation, often staying on ventilators for weeks at a time, says Kumar, who describes many of the Winnipeg

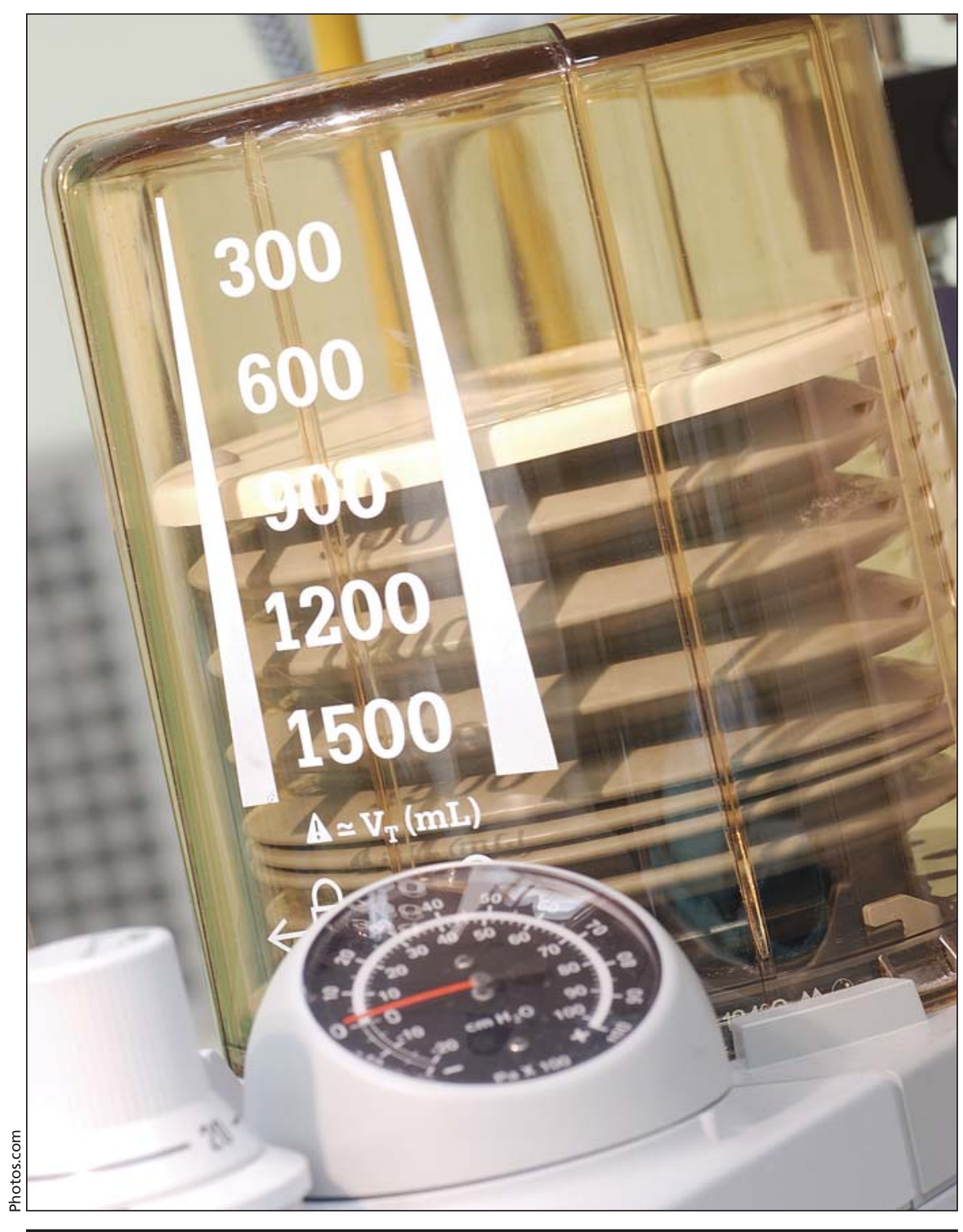

The Public Health Agency of Canada says it wants to buy another 370 ventilators as part of its National Emergency Stockpile System.

patients he treated as "the most difficult patients in terms of ventilator management that I've ever seen in my 20 years of practice."

"To a great extent, among adults, this is an ICU disease," Kumar notes. Many of those who were admitted needed highfrequency oscillatory ventilation - a jetlike ventilation that oscillates oxygen into patients at the rate of 300 times a minute or more. This therapy also requires nitrous oxide and airway pressure relief, as well as other advanced ventilation techniques, he adds. About half a dozen Canadian patients also had to be placed on heart-lung bypass machines to give them extra-corporeal membrane oxygenation or likely would have died.

Most hospitals in Canada do not have oscillating ventilators, and there are only a few centres that can do heartlung bypass. That has left critical care 
physicians concerned about the country's readiness if a second pandemic (H1N1) 2009 wave hits in the fall.

"I don't think that everybody realizes that the pandemic stores, the emergency store of ventilators that a lot of people are depending upon in case of emergency, simply aren't advanced enough to take care of these patients," says Kumar.

Ventilators made more than 15 years ago and those routinely used in emergency rooms aren't advanced enough for this type of therapy, he adds. However, older ventilators may be useful for the less severely injured.

In a written response to CMAJ questions, the Public Health Agency of Canada (PHAC) confirmed that of the additional 370 ventilators it is trying to purchase as part of its National Emergency Stockpile System, none are oscillating ventilators. PHAC does not have a stockpile of heart-lung bypass machines.

Nurses and respiratory technologists will be as critical if Canadian hospitals see even 3.5 times more cases of pandemic (H1N1) 2009 patients with lung injuries in a second wave - and that is a conservative estimate, says Dr. Allison McGeer, director of infection control at Toronto's Mount Sinai Hospital. Like Kumar and Fowler, she is concerned that ICUs may become the choke point in the health care system come fall.

Unlike ICUs in the United States, which routinely keep some beds empty and ventilators free, Canadian units normally run at $90 \%-95 \%$ full sometimes more, with patients waiting in emergency before being admitted. "It's very efficient from a systems point of view, but it means we have no surge capacity in our ICUs in Canada," says McGeer. Even so, "I am less worried about the ventilator supplies than I am about the staff resources to care for them," she adds.

Hospitals should also be stockpiling sedatives, paralytics and antibiotics, because the ventilated patients with pandemic (H1N1) 2009 often require "massive" sedation.

Administrators should also be making plans to designate staff to make tough triage choices, Kumar says. "The idea of, how you triage 2 young people to a single ventilator — that's a very difficult issue."

Fowler is also worried that Canadian hospitals will have to limit resources to people who are very sick because of inadequate capacity. "That's a position we haven't found ourselves in throughout the history of medicare in Canada."

With each province and region developing its own pandemic plan, the Canadian Critical Care Society is concerned that "from a national perspective, there's no coordinated effort to help with resource utilization and sharing that sort of resource planning," says Dr. John Granton, a Toronto ICU physician and the Society's president.

Pandemic planning has largely been devoted to securing a vaccine and rolling out immunization, but federal oversight is needed to ensure provincial licensing requirements are waived and malpractice insurance is extended so that, if necessary, health care professionals and medical equipment can be shared between jurisdictions, Granton says. — Laura Eggertson, Ottawa, Ont.

DOI:10.1503/cmaj.109-3005

\section{Medical literature, made to order}

$\mathrm{M}$ any publishers of scientific journals have divisions that produce customized publications for drug companies, and some experts in medical publishing standards say it's becoming increasingly difficult to distinguish science from marketing.

"The whole area of the pharmaceutical relationship with journals in this sort of gray literature is not really well spelled out, mainly because it's often not clear where editorial responsibility lies," says Dr. Virginia Barbour, a PLoS Medicine editor and secretary of the Committee on Publication Ethics, a United Kingdom-based charitable organization whose membership is comprised primarily of the editors-in-chief of scientific journals.

The 6 fake medical journals that recently brought scientific publisher Elsevier heaps of negative publicity were released under the company's communications division, Excerpta Medica Communications. The division partners with clients "in the pharmaceutical and biotech industries to educate the global health community," according to its website (www.excerptamedica.com).

"The biggest issue here was the lack of disclosure," says Barbour.

One case study posted on the website describes the division's efforts to promote a client's cardiovascular product in a crowded market. It did this by producing a company-sponsored journal (the word "journal" was replaced on the website by "publication" sometime after $C M A J$ spoke with representatives from Excerpta Medica Communications in mid-July) to "establish this client as one of the industry's authorities on cardiovascular disease."

Elsevier has admitted that the pharmaceutical industry-funded "Aus-

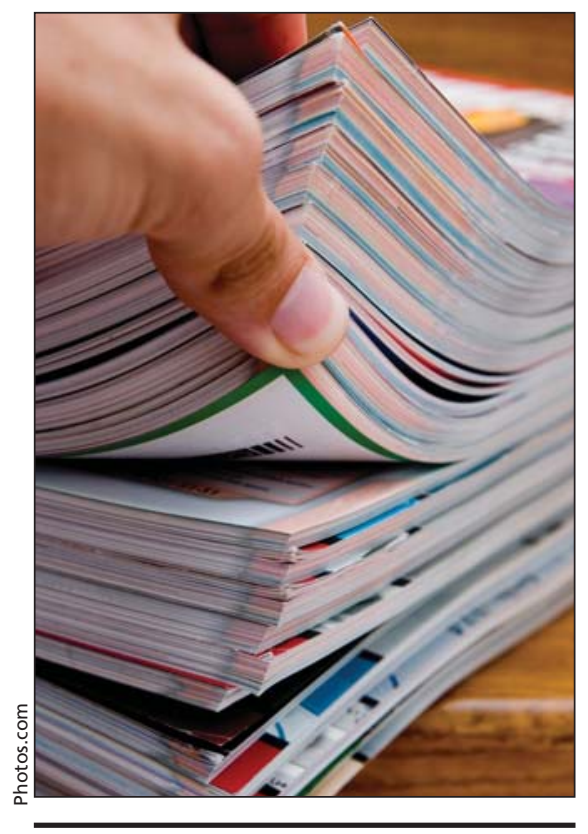

Critics of the pharmaceutical industry's influence on academic publishing say it is becoming more difficult to tell if the content of medical journals is science or marketing. 